\title{
Professor Roger Sutton DM, FRCPC: in memoriam
}

\author{
William G Robertson
}

Received: 18 November 2014 / Accepted: 19 November 2014 / Published online: 29 November 2014

(C) Springer-Verlag Berlin Heidelberg 2014

It was with great sadness that we learned belatedly of the death of Professor Emeritus Roger Sutton on 10th September 2014 in Vancouver after a 2-year battle with bladder cancer. His death is a great loss, not only to his wife Wendy and their two daughters, Fiona and Nicola, but also to the "stone community". Although his main research interests were in urolithiasis, he also carried out research into disorders of calcium metabolism and osteoporosis. In 1968, he and I were among the attendees at the Renal Stone Research Symposium in Leeds which was the first in what later became the prestigious fouryearly series of International Symposia on Urolithiasis. Subsequently, he attended all but one of the remaining Symposia, including the latest one in Ouro Preto, Brazil, in 2012.

Roger graduated in medicine at the University of Oxford followed by post-graduate training at University College Hospital London (UCLH). He specialised in nephrology and not long after emigrated with his wife and young family to Canada in the early 1970s. He worked initially at the Royal Victoria Hospital and McGill University in Montreal, but in the mid-1970s moved to Vancouver, where he became Head of the Department of Medicine in Vancouver General Hospital and President of the Canadian Society of Nephrology. In 1978, he was awarded the prestigious Medal in Medicine of the Royal College of Physicians of Canada for his research activities.

Roger was an inspirational teacher and possessed an enquiring mind which encouraged others to collaborate with him in his research endeavours. As a consequence, many of his students and fellows have subsequently been appointed to important senior positions in medicine. He had a quiet and modest approach to life, coupled with a puckish sense of humour which made him many friends in the stone field and, as an internationally recognised expert in the field, he was invited to lecture at countless stone conferences throughout the world. His international reputation eventually led him to be invited in 1993 to take up the post as Head of the Department of Medicine at the Aga Khan University in Karachi where he later became Dean of Health Sciences, before returning to Vancouver in 2000. Roger had an impressive CV with a long and enviable list of peer-reviewed publications.

Roger had a life-long interest in ornithology and often at international conferences he would take himself off to search out and photograph some particularly rare species peculiar to that part of the world. As an accomplished photographer, he accumulated over the years an impressive collection of high-quality photographs which is the envy of many of his fellow "twitchers" throughout the world.

Roger took great joy in communicating with family and friends and he will be greatly missed not only by them, but also by all his colleagues in the calcium and stone fields world-wide. At this sad and difficult time our thoughts and condolences go out to Wendy, Fiona and Nicola and their extended families.

W. G. Robertson $(\bowtie)$

University of Oxford, Oxford, UK

e-mail: robertsonwilliam67@gmail.com 